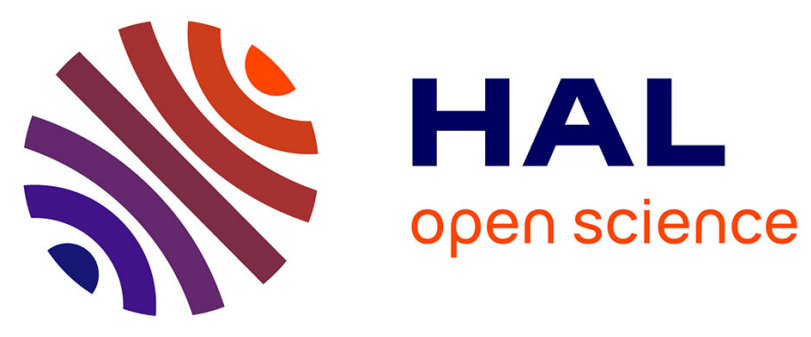

\title{
Design and fabrication of photonic crystal thin film photovoltaic cells
}

Guillaume Gomard, Ounsi El Daif, Emmanuel Drouard, Xianqin Meng, Anne Kaminski, Alain Fave, Mustapha Lemiti, Enric Garcia-Caurel, Pere Roca I Cabarrocas, Christian Seassal

\section{To cite this version:}

Guillaume Gomard, Ounsi El Daif, Emmanuel Drouard, Xianqin Meng, Anne Kaminski, et al.. Design and fabrication of photonic crystal thin film photovoltaic cells. Photonics for solar energy systems III : ( 13-15 April 2010, Brussels, Belgium ) Photonics for solar energy systems No3, Bruxelles BELGIQUE (2010) SPIE Photonics Europe No03, Bruxelles BELGIQUE (2010), Apr 2010, Brussels, Belgium. pp./, 10.1117/12.854383 . hal-00666214

\section{HAL Id: hal-00666214 https://hal.science/hal-00666214}

Submitted on 3 Feb 2012

HAL is a multi-disciplinary open access archive for the deposit and dissemination of scientific research documents, whether they are published or not. The documents may come from teaching and research institutions in France or abroad, or from public or private research centers.
L'archive ouverte pluridisciplinaire HAL, est destinée au dépôt et à la diffusion de documents scientifiques de niveau recherche, publiés ou non, émanant des établissements d'enseignement et de recherche français ou étrangers, des laboratoires publics ou privés. 


\title{
Design and fabrication of photonic crystal thin film photovoltaic cells
}

\author{
Guillaume Gomard $^{\mathrm{a}, \mathrm{b}}$, Ounsi El Daif ${ }^{\mathrm{a}, \mathrm{b}}$, Emmanuel Drouard ${ }^{\mathrm{a}}$, Xianqin Meng ${ }^{\mathrm{a}, \mathrm{b}}$, Anne Kaminski ${ }^{\mathrm{b}}$, \\ Alain Fave $^{\mathrm{b}}$, Mustapha Lemiti ${ }^{\mathrm{b}}$, Enric Garcia-Caurel ${ }^{\mathrm{c}}$, Pere Roca i Cabarrocas ${ }^{\mathrm{c}}$, Christian Seassal ${ }^{\mathrm{a}}$ \\ ${ }^{a}$ Université de Lyon, Institut des Nanotechnologies de Lyon-INL, UMR CNRS 5270 \\ Ecole Centrale de Lyon, F-69134 Ecully, France; \\ ${ }^{\mathrm{b}}$ Université de Lyon, Institut des Nanotechnologies de Lyon-INL, UMR CNRS 5270 \\ INSA Lyon, F-69621 Villeurbanne, France \\ ${ }^{\mathrm{c}}$ LPICM, CNRS UMR 7647, Ecole Polytechnique, Palaiseau, France
}

\begin{abstract}
We present the integration of an absorbing planar photonic crystal within a thin film photovoltaic cell. The devices are based on a stack including a hydrogenated amorphous silicon P-i-N junction surrounded by TCO layers, with a back metallic contact. Optical simulations exhibit a significant increase of the integrated absorption in the 300-720nm wavelength range. The global electro-optical characteristics of such a new solar cell, and the impact of surface passivation, are also discussed. Carrier generation rate maps calculated by optical simulations are introduced as input data in a commercial electrical simulation software. The fabrication of such a device is finally addressed, with a specific focus on the use of low cost nanopatterning processes compatible with large areas.
\end{abstract}

Keywords: Photonic crystal, Photovoltaic solar cell, Thin film solar cell, Hydrogenated amorphous silicon.

\section{INTRODUCTION}

In order to optimize light trapping and absorption in thin film solar cells, various concepts inspired from nanophotonics were recently proposed, including plasmonic, diffraction and slow light effects [1-2]. Among the most promising concepts, it was recently predicted and demonstrated that the absorption efficiency of thin absorbing film like hydrogenated amorphous silicon $(\mathrm{a}-\mathrm{Si}: \mathrm{H})$, may be greatly increased by periodically patterning it as a planar photonic crystal (PC) [3-5]. This enables to couple the incident light into the Bloch modes of the PC, in which photons are trapped during a lifetime $\tau_{\mathrm{p}}$. Since this trapping time may exceed the photon travelling time in a simple unpatterned layer, the absorption may be enhanced, which is all the more relevant for wavelengths where the absorption coefficient tends to decrease, e.g. above $600 \mathrm{~nm}$ for a-Si:H. Moreover, we predicted that if $\tau_{\mathrm{p}}$ is around the time $\tau_{\mathrm{a}}$ corresponding to the absorption length in the considered material, incident light coupling into the PC Bloch modes is optimized, which further increases the incident light absorption [3]. In the case of photovoltaic (PV) devices, the difficulty consists in providing PC Bloch modes to incident light corresponding to the full range where the absorbing material is efficient, i.e. 300$720 \mathrm{~nm}$ for a-Si:H. This may be achieved in the case of a strongly multimode planar PC; in practice, in order to select the geometrical parameters of such a structure, including the lattice parameter, the width of the air slits or holes, they should be scanned in order to find optimum configuration. We demonstrated that such absorbing PCs, and their surface addressable Bloch modes, may be used to control the absorption over such a wide spectral range, with an absorption increase of around 50\% in the case of a planar 1D PC, compared to an unpatterned layer [4]. Additionally, due to the intrinsic nature of these modes, which exhibit flat dispersion curves, the absorption efficiency is relatively independent to the angle of incidence [4]. Various schemes were recently discussed in order to achieve the integration of absorbing PCs in a full solar cell, including their electromagnetic environment [5-7]. It is still necessary to pave the way from such preliminary designs and demonstrations to real solar cells.

In this paper, we propose to combine a-Si:H absorbing PCs, transparent conductive layers (TCO) and metallic electrodes as a full PV cell. In section 2, we present this design and the expected optical properties. In section 3, we discuss on the electrical properties of such PV devices, as predicted by simulation. Lastly, in section 4, we present the underway technological development in order to fabricate the solar cells.

Photonics for Solar Energy Systems III, edited by Ralf B. Wehrspohn, Andreas Gombert, Proc. of SPIE Vol. $7725,77250 \mathrm{M} \cdot$ @ C 2010 SPIE · CCC code: $0277-786 \mathrm{X} / 10 / \$ 18 \cdot$ doi: $10.1117 / 12.854383$ 


\section{OPTICAL DESIGN OF THE PHOTONIC CRYSTAL-ASSISTED SOLAR CELL}

The proposed device is based on a stack deposited on a low cost substrate like glass, and composed of a silver-based reflector on the back side, a zinc oxide layer and finally, an a-Si:H layer overlaid by an indium tin oxide (ITO) layer. The last two layers are patterned as 1D or 2D planar PCs. Fig. 1a exhibits the schematic view of the device in the case of a 2D PC with a square symmetry. Incident light is expected to be preferentially absorbed in the a-Si:H layer, while the photogenerated carriers are collected by the ITO and ZnO layers, which behave as TCOs. The photocarriers are then collected on the top by the ITO layer, and then by a metallic grid (not shown in the figure), while those collected by the bottom contact just pass through the $\mathrm{ZnO}$ layer and are collected by the Ag electrode. The ITO layer intrinsic properties and thickness $(50 \mathrm{~nm})$ enables lateral charge transfer over a few hundreds of micrometers, to the metallic electrodes. Its thickness is limited in order to reduce the optical losses. The situation is radically different in the case of the bottom electrode: the $\mathrm{ZnO}$ layer acts as a conductive spacer, while the lateral charge transfer occurs in the $\mathrm{Ag}$ electrode. $\mathrm{ZnO}$ was selected although its conductivity is not as good as that of ITO, because of its low optical absorption. In terms of optical behaviour, the ITO layer is expected to act as an anti-reflection coating, while the back Ag will reflect non absorbed light. The $\mathrm{ZnO}$ spacer layer is expected to control the interferences between the PC Bloch modes and the $\mathrm{Ag}$ mirror. The thickness of the a-Si:H layer was arbitrarily fixed at $100 \mathrm{~nm}$, a value significantly lower than in the standard solar cells using such a material. In this case the minority carriers diffusion length $(\sim 150 \mathrm{~nm})$ is higher than the layer thickness; which should lead to an improved carrier collection, even in the light-soaked state of the a-Si:H solar cell.

The absorption of the structure described above is calculated by Rigorous Coupled Wave Analysis (RCWA) [8-9]. The efficiency of such a solar cell is directly related to the integrated solar light intensity absorption in the a-Si:H layer between $300 \mathrm{~nm}$ and $720 \mathrm{~nm}$; this parameter will thus be used as a criteria of comparison between patterned and unpatterned structures. The AM1.5G solar spectral intensity distribution is applied to the incident plane wave, illuminating the surface at normal incidence. The geometrical parameters of the structure to be optimized were scanned, and RCWA simulation was performed for each set of parameters. More precisely, we scanned the PC lattice parameter L (between $0.3 \mu \mathrm{m}$ and $0.7 \mu \mathrm{m}$ ) and the air filling factor, $\mathrm{ff}_{\text {air }}=\mathrm{D} / \mathrm{L}$ (between 0.3 and 0.7 ), $\mathrm{D}$ being the $\mathrm{PC}$ holes diameter. Various $\mathrm{ZnO}$ layer thicknesses were also considered, between 0 and $130 \mathrm{~nm}$. A maximal integrated absorption of about $82 \%$ (over the whole stack) is reached for $\mathrm{L}=0.38 \mu \mathrm{m}, \mathrm{ff}_{\mathrm{air}}=62.5 \%$ and for a $\mathrm{ZnO}$ thickness of $100 \mathrm{~nm}$. This value represents a $28 \%$ relative increase compared to the only $64.3 \%$ absorption efficiency obtained in the case of the reference stack, with similar thicknesses and no patterning. One should note that if we only consider the useful part of the absorption, i.e. absorbed light in a-Si:H, the integrated absorption is reduced to $65.7 \%$ in the case of the optimal PC structure, and $51.7 \%$ in the case of the reference stack.

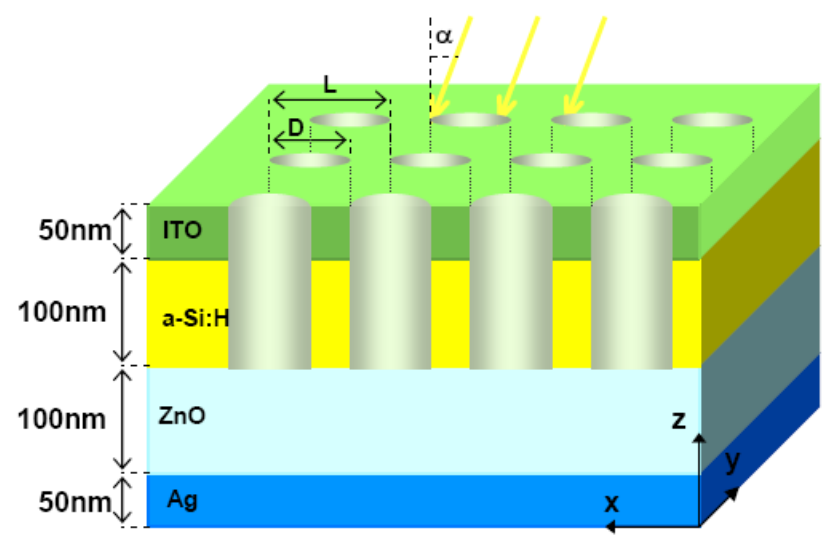

(a)

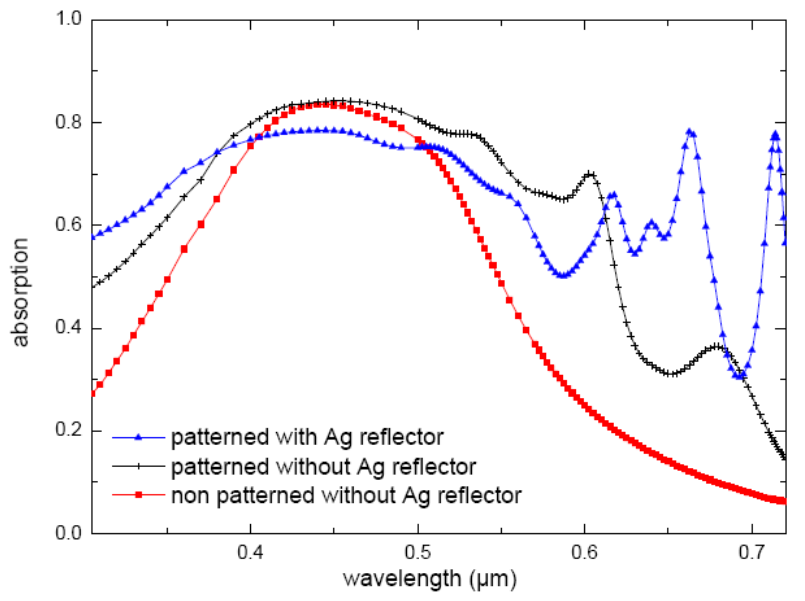

(b)

Fig. 1: Schematic view of a planar 2D PC-assisted a-Si:H solar cell (a) and calculated absorption spectrum for the optimized PC-assisted solar cell (in blue, triangles), for the same structure without the Ag layer (in black, crosses) and for the non patterned structure without the Ag layer (in red, squares)

The spectrum calculated for the optimized structure is displayed in Fig. 1b, together with two spectra corresponding to a structure without the $\mathrm{Ag}$ layer, and the non patterned layer, also without the metallic mirror. On this spectrum, two 
spectral domains appear. At short wavelengths, a very broad absorption is obtained, up to about $500 \mathrm{~nm}$. In this regime, the absorption coefficient of a-Si:H is so large that light may be fully absorbed in a layer as thin as $100 \mathrm{~nm}$. The Bloch modes of the PC structure are then useless to increase the incident light absorption; still, patterning may play a positive role in decreasing the reflection at the front surface, due to a relatively low "mean refractive index". This leads to a higher absorption at the shortest wavelengths in the case of the patterned structures. Now, considering the spectral range above 500nm, a series of absorption peaks appear in the case of the optimized structure. Each peak corresponds to a PC resonant mode, with a good "impedance matching" with regards to the incident light. The number of observed peaks clearly illustrates the multimode character of our PC structure. Some of these peaks are still visible on the patterned structure without the Ag layer, but with a slightly tuned wavelength, and more importantly with a modified absorption. This shows that the Ag mirror plays a key role in the control of the incident light coupling, and on the photon interaction with the absorbing medium. Finally, combining different effects, the photonic patterning clearly increases the absorption efficiency of the structure both at short and at long wavelengths.

\section{ELECTRICAL SIMULATION OF THE PC-ASSISTED SOLAR CELL}

Since the a-Si:H thickness was chosen to be smaller than the diffusion length of the minority carriers, the computed absorption increase is expected to subsequently optimize the conversion efficiency. However, it should be noted that the impact of surface recombination is not considered in the results presented above. A more thorough description of our device should therefore include not only the photonic structure impact on the optical absorption, but also surface and bulk carrier recombination. To predict the properties of our device, and to include these different aspects, we performed full opto-electric simulation using an original scheme. Optical absorption maps at different wavelengths are calculated by RCWA. These are then processed in order to calculate carrier generation rate maps, which do not depend anymore on the incident light wavelength. Such maps are then introduced in the SILVACO electrical simulator (ATLAS).

In this study, we considered a planar 1D PC structure, for simplicity. The optimum geometrical parameters were first determined by performing a new set of RCWA simulations. Using the same method as in section 2, integrated absorption was calculated in the $300-720 \mathrm{~nm}$ spectral range, for different geometrical parameters (lattice parameter and air filling factor). We considered the same thicknesses as in section 2. A maximum absorption of $64 \%$ is calculated in a-Si: $\mathrm{H}$ for TE incident light, for a $480 \mathrm{~nm}$ lattice parameter, and a 0.275 air filling factor. The integrated absorption for TM polarized incident light is of $59 \%$ for the same structure. This is still to be compared to the $52 \%$ absorption in the case of the reference unpatterned structure. Figure 2 shows the generation rate maps calculated in the case of the optimized 1D PC structure and for the reference unpatterned structure.

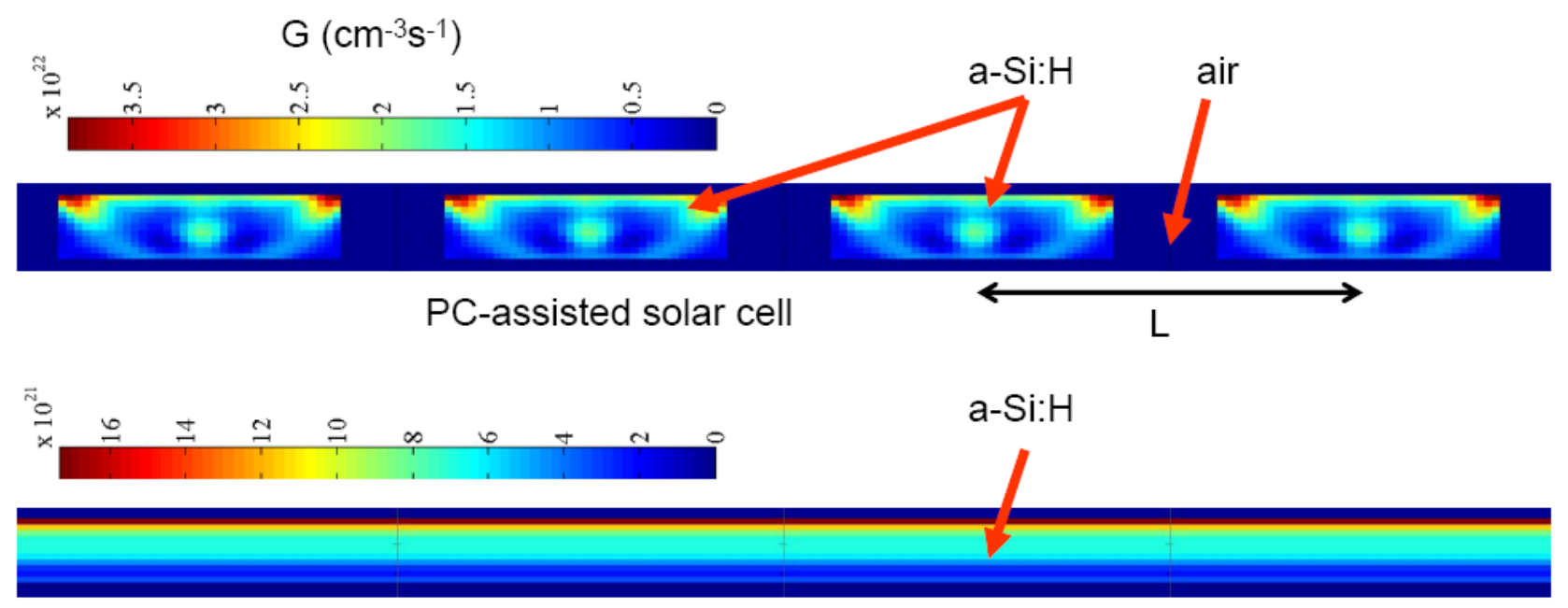

\section{Reference structure}

Fig 2 : Generation rate maps (cross-section) calculated for an optimized planar 1D PC-assisted a-Si solar cell (a) and for a the reference stack with no PC and the same layers and thicknesses (b) 
These carrier generation rate maps were then used as inputs in SILVACO 2D simulations. We considered an a-Si:H ni-p junction with a $10 \mathrm{~nm}$ thick n-doped layer $\left(5.10^{18} \mathrm{~cm}^{-3}\right)$, a $80 \mathrm{~nm}$ thick intrinsic layer $\left(\mathrm{n}\right.$ or $\left.\mathrm{p}, 5.10^{15} \mathrm{~cm}^{-3}\right)$, and a $10 \mathrm{~nm}$ thick p-doped layer $\left(5.10^{18} \mathrm{~cm}^{-3}\right)$. We also considered effective carrier lifetimes: $\tau_{\mathrm{n}}=10^{-5} \mathrm{~s}, \tau_{\mathrm{p}}=10^{-7} \mathrm{~s}$. The other parameters used were $\mathrm{Eg}=1.7 \mathrm{eV}, \mu_{\mathrm{n}}=1 \mathrm{~cm}^{2} . \mathrm{V}^{-1} \cdot \mathrm{s}^{-1}$, and $\mu_{\mathrm{p}}=10^{-2} \mathrm{~cm}^{2} \cdot \mathrm{V}^{-1} \cdot \mathrm{s}^{-1}$. It should be noted that the results of these simplified simulations essentially enable the comparison between such a reference structure and PC-assisted solar cells. We will therefore discuss on tendencies rather than on the absolute values of the calculated characteristics.

On the reference structure, the predicted conversion efficiency is $7.93 \%$, with a $0.98 \mathrm{~V} \mathrm{Voc}$, and $\mathrm{Jsc}=9.25 \mathrm{~mA} / \mathrm{cm}^{2}$. In the case of PC-assisted solar cells, the influence of the surface recombination of the carriers on the sidewalls of the patterns was investigated, considering surface recombination rates $\mathrm{S}$ from 0 to $10^{7} \mathrm{~cm} \cdot \mathrm{s}^{-1}$ and constant front surface recombination. Fig. 3 exhibits the I(V) characteristics for various values of S, compared with the reference structure.

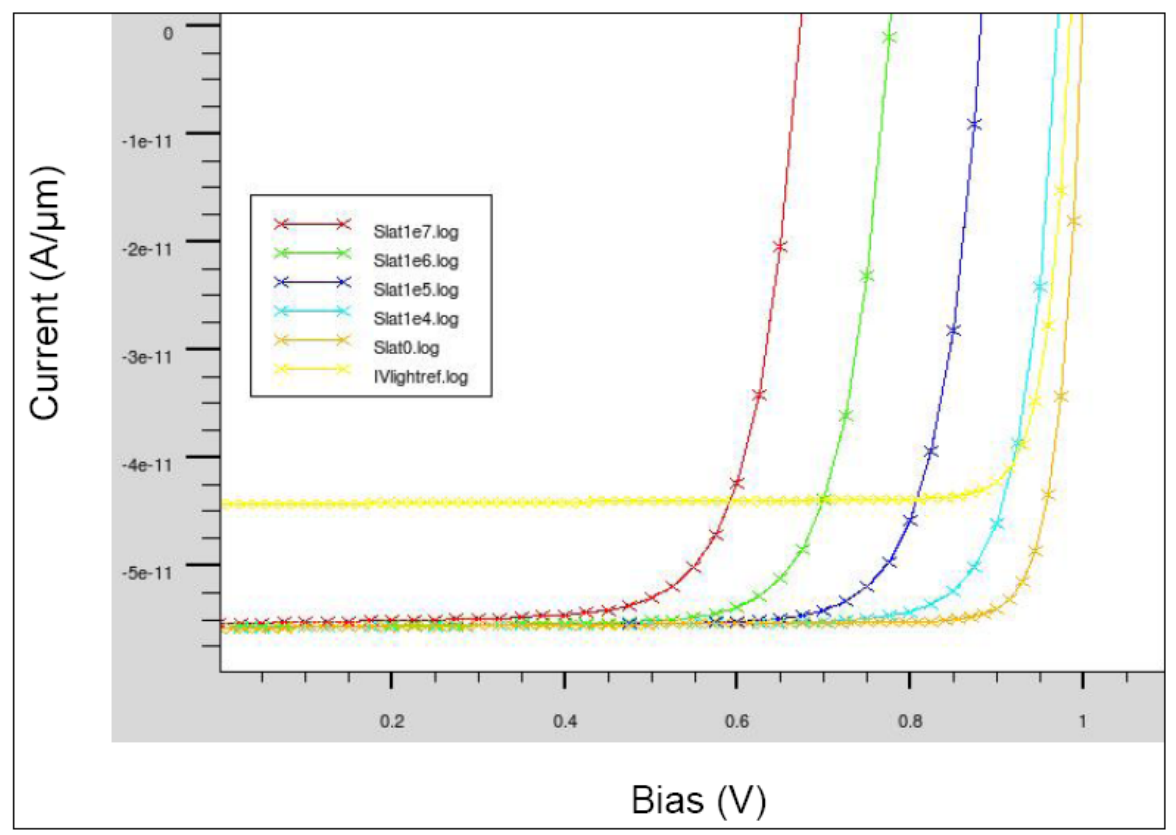

Fig. 3: I(V) characteristics of PC-assisted solar cells for various lateral surface recombination rates (from 0 to $10^{7} \mathrm{~cm} . \mathrm{s}^{-1}$ ), and for the reference cell, without PC structure.

Table 1. Main extracted values from SILVACO simulations: short-circuit current, open circuit voltage, and conversion efficiency.

\begin{tabular}{|l|l|l|l|}
\hline $\mathrm{S}(\mathrm{cm} / \mathrm{s})$ & Jsc $(\mathrm{mA} / \mathrm{cm} 2)$ & $\operatorname{Voc}(\mathrm{V})$ & Efficiency $\eta(\%)$ \\
\hline Reference cell & 9.25 & 0.98 & 7.93 \\
\hline 0 & 11.65 & 1 & 10.14 \\
\hline $10^{4}$ & 11.65 & 0.97 & 9.28 \\
\hline $10^{5}$ & 11.64 & 0.88 & 8.12 \\
\hline $10^{6}$ & 11.63 & 0.775 & 6.91 \\
\hline $10^{7}$ & 11.56 & 0.67 & 5.71 \\
\hline
\end{tabular}

From the extracted values displayed in Table 1, it clearly appears that $\mathrm{J}_{\mathrm{sc}}$ is increased in the case of the PC-assisted solar cell, due to the higher integrated absorption. The increasing surface recombination rates tend to decrease $\mathrm{V}_{\mathrm{oc}}$, and therefore the conversion efficiency. As a result, the efficiency of such a device may be increased using a PC, provided the surface recombination rate is about $10^{5} \mathrm{~cm} \cdot \mathrm{s}^{-1}$ or below. A final passivation of the PC holes or slits sidewalls will therefore be necessary in order to take full profit of the absorption increase. 


\section{FABRICATION OF PC-ASSISTED SOLAR CELLS}

Fabrication of these novel devices is based on a combination of classical thin film PV cell processing, and nanopatterning over large areas. The stack described in section 2 is first deposited on a glass substrate; in particular the aSi:H P-i-N junction are deposited in a standard capacitively coupled radio frequency glow discharge system [10]. The PC structure may be patterned on such a stack using various kinds of nanolithography techniques. Laser holography was selected since it is a mask-less technology that enables fast patterning of 1D or square symmetry 2D periodic structures, corresponding to the design presented above [11]. Fig. 4a displays an SEM view of a 2D PC patterned exposed in NEB22 resist using a $266 \mathrm{~nm}$ laser. Such patterns are then transferred into a $\mathrm{SiO}_{2}$ hard mask deposited on top of the stack. The $\mathrm{SiO}_{2}$ pattern is then transferred to the ITO and a-Si:H layers, respectively by $\mathrm{CH}_{4}: \mathrm{H}_{2}$ and $\mathrm{SF}_{6}$ :Ar based reactive ion etching (RIE) processes at low pressure. Fig $4 \mathrm{~b}$ presents a cross-section view of a patterned a-Si:H layer, in the case of a 1D PC structure. This micrograph shows that the sidewalls are fairly vertical. Fig. $4 \mathrm{c}$ is a cross-section view of a the patterned full structure, including ITO and a-Si:H layers, and the unpatterned layers underneath.

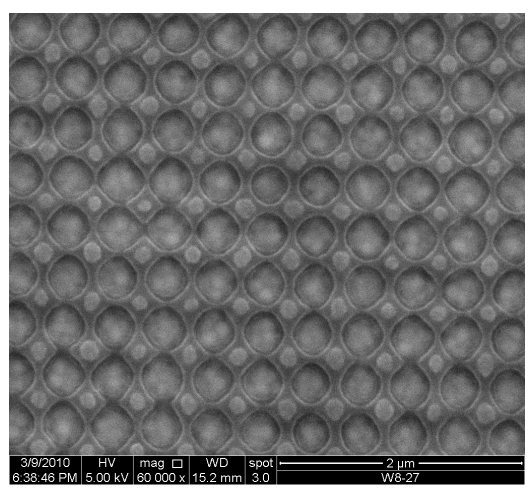

(a)

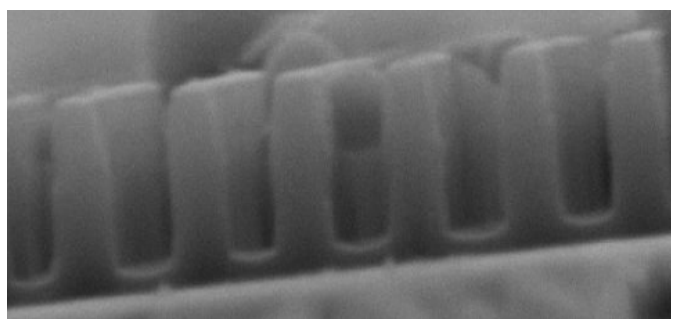

(b)

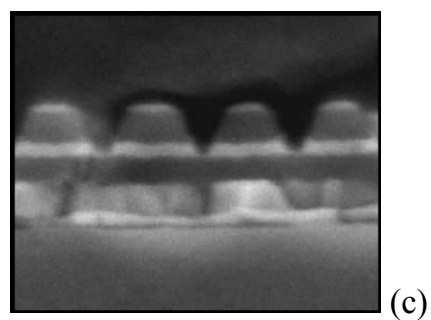

Fig. 4: SEM top view of the 2D patterned processed in the resist by laser holography (a), and cross-section view of a patterned a-Si layer (b), and of the patterned stack (c).

The metallic top and bottom electrodes are then deposited on mesa fabricated by classical UV lithography and RIE, along the scheme presented in Fig. 5a. Metallic contacts fabricated by lift-off are presented on Fig. 5b.

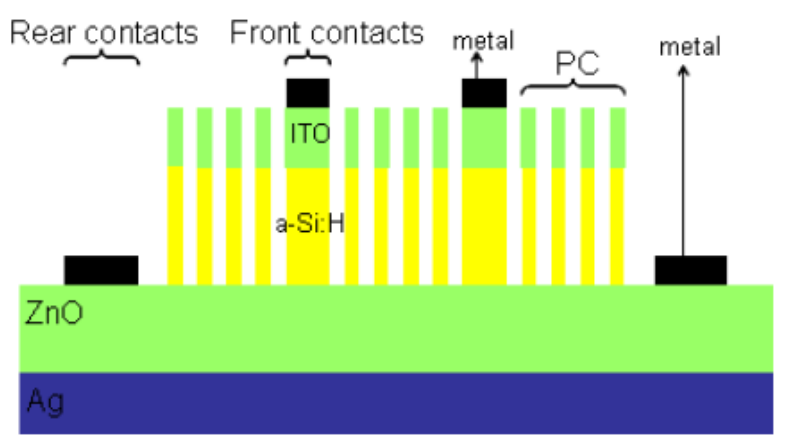

(a)

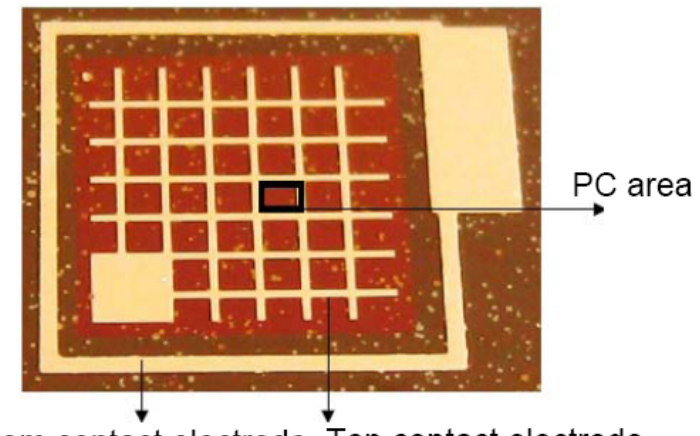

Bottom contact electrode Top contact electrode

(b)

Fig. 5: Schematic cross-section of the fully fabricated PC-assisted solar cell, including the metallic electrodes deposited on top of the TCO layers (a), and microscope view of the metallic contacts deposited on a test structure (b). 


\section{CONCLUSION}

We presented the design of a fully integrated a-Si:H-based solar cell assisted by a planar PC patterned in the absorbing layer. Such a design enables to increase the absorption of incident light up to $65.7 \%$, in the $100 \mathrm{~nm}$ thin a-Si:H layer, and in the whole $300-720 \mathrm{~nm}$ spectral range. Further increase of the absorption is possible by adapting more accurately the thickness of some of the layers; in particular in order to provide more efficient anti-reflexion properties. The subsequent impact of the patterning on the conversion efficiency was calculated by combining RCWA and SLILVACO simulations. Provided an efficient PC sidewalls passivation is performed, a relative increase of the conversion efficiency of around $30 \%$ is expected in the case of optimized PC structures. Further improvements should be possible by optimizing further the geometrical parameters of this solar cell design, and considering both electrical and optical properties of the combined layers. Progress towards the fabrication of the devices was also discussed, with a specific focus on processes providing cheap nanopatterning over large areas. Fabrication and test of first PC-assisted a-Si:H PC-assisted solar cell is currently underway.

\section{ACKNOWLEDGEMENTS}

This work was performed in the frame of the ANR Photovoltaic program, through the SPARCS project. We thank Drs. C. Jamois, X. Letartre and P. Viktorovitch for helpful discussions, the NanoLyon Technology Platform and R. Perrin for efficient support, and Prof. Heonsu Jeon's group, from SNU, for his support on laser holography.

\section{REFERENCES}

[1] F. J. Beck, A. Polman, and K. R Catchpole, "Tunable light trapping for solar cells using localised surface plasmons,” J. Appl. Phys. 105, 114310 (2009)

[2] L. Zeng, P. Bermel, Y. Yi, B. A. Alamariu, K. A. Broderick, J. Liu, C. Hong, X. Duan, J. Joannopoulos and L. C. Kimerling, "Demonstration of enhanced absorption in thin film Si solar cells with textured photonic crystal back reflector," Appl. Phys. Lett. 93, 221105 (2008)

[3] C. Seassal, Y. Park, A. Fave, E. Drouard, E. Fourmond, A. Kaminski, M. Lemiti, X. Letartre, P. Viktorovitch, "Photonic crystal assisted ultra-thin silicon photovoltaic solar cell," SPIE Photonics Europe, Photonics for Solar Energy Systems, Strasbourg, 7-8 april 2008, Proceedings of SPIE Volume 7002, 700207

[4] Y. Park, E. Drouard, O. El Daif, X. Letartre, P. Viktorovitch, A. Fave, A. Kaminski, M. Lemiti, C. Seassal, "Absorption enhancement using photonic crystals for silicon thin film solar cells," Opt. Expr. 1714312 (2009)

[5] O. El Daif, Y. Park, E. Drouard, A. Fave, A. Kaminski, M. Lemiti, X. Letartre, P. Viktorovitch, S. Ahn, H. Jeon, C. Seassal, "Photonic crystal band engineering for enhanced absorption in thin amorphous silicon solar cells," 24th European Photovoltaic Solar Energy Conference and Exhibition, Hambourg, 21-25 september 2009

[6] S. Zanotto, M. Liscidini, and L. C. Andreani, "Light trapping regimes in thin-film silicon solar cells with a photonic pattern," Opt. Express 18, 4260-4274 (2010)

[7] Shrestha Basu Mallick, Mukul Agrawal, and Peter Peumans, "Optimal light trapping in ultra-thin photonic crystal crystalline silicon solar cells," Opt. Express 18, 5691-5706 (2010)

[8] M. G. Moharam and T. K. Gaylord, "Rigorous coupled-wave analysis of planar-grating diffraction," J. Opt. Soc. Am. 71, 811-818 (1981)

[9] http://camfr.sourceforge.net/

[10] P. Roca i Cabarrocas, J.B. Chevrier, J. Huc, A. Lloret, J.Y. Parey and J.P.M. Schmitt, "A fully automated hot-wall multiplasma-monochamber reactor for thin film deposition," J. of Vac. Sci. and Technol. A9, 2331 (1991)

[11] C. O. Cho, Y. G. Roh, Y. Park, H. Jeon, B. S. Lee, H. W. Kim and Y. H. Choe, "Photonic Crystal Slab Waveguides Fabricated by the Combination of Holography and Photolithography,” Jpn. J. Appl. Phys. 43, 1384 (2004) 